\title{
Examining the Relationship of Organizational Agility and Organizational Forgetting with Organizational Effectiveness
}

\author{
Gholamreza Mohammad Ghasemi \\ Educational Management, University of Sistan and Baluchestan, Zahedan, Iran \\ Email: tarjomeh4u@gmail.com
}

Received 8 November 2014; accepted 14 February 2015; published 30 June 2015

Copyright (C) 2015 by authors and Scientific Research Publishing Inc.

This work is licensed under the Creative Commons Attribution International License (CC BY).

http://creativecommons.org/licenses/by/4.0/

(c) (i) Open Access

\section{Abstract}

This study aimed to investigate the relationship of organizational agility and organizational forgetting with organizational effectiveness among staff of the education administration of Zahedan. The population of this study included a total of 645 staff of the education administration of Zahedan who served in the 2013-14 school year. Using the Krejcie-Morgan table, 200 individuals were selected through applying stratified random method. To collect data, three questionnaires including Organizational Agility [1], Organizational Forgetting [2] and Organizational Effectiveness [3] were used. Content validity of these questionnaires was approved by the faculty members of the Department of Management and confirmatory factor analysis was used to ensure the results. In addition, Cronbach's alpha for the scales of organizational agility, organizational effectiveness and organizational forgetting was calculated, which was $0.73,0.74$ and 0.76 , respectively. The results showed that there was a significant positive correlation between organizational agility and organizational effectiveness. Moreover, there was a significant positive relationship between organizational forgetting and organizational agility. In addition, there was a significant positive relationship between organizational forgetting and the components of organizational effectiveness. Additionally, there was a significant positive correlation between organizational agility and the components of organizational effectiveness.

\section{Keywords}

Organizational Agility, Organizational Forgetting, Organizational Effectiveness 


\section{Introduction}

Nowadays, the dominant thinking assumes and defines organizations as entities that not only respond to the external environment, but also actively shape and influence their own environment. Only organizations can continue to survive and compete in competitive markets that are able to achieve such capabilities [4]. In other words, previous approaches and solutions have lost their ability to face organizational problems and the external environment or are better to be replaced with recent approaches. Thus, one way of responding to these changes is organizational agility. In fact, organizational agility is a new paradigm for the development of organizational engineering and competitiveness. Agile organizations are open to learn anything new that increases their efficiency by taking advantage of new opportunities [5]. The foundation of agile is the integration of systems/information technology, personnel, business processes and equipment within a coordinated and flexible organization to quickly respond to events and changes in the environment [6]. Organizational agility is the ability to sense and react quickly and successfully to environmental changes. Like producers other organizations and institutions are forced to seek agility to compete in the 21th century, because modern organizations face growing pressure to find new ways to compete effectively in the global market dynamics [7]. Agility improves organization's ability to supply high quality products and services and thereby is an important factor for the productivity [8]. Moreover, due to the speed and acceleration of changes in today's world, it seems that organizational forgetting is a factor that helps managers and organizations to solve problems and realize their goals, since organizations face a great deal of useful and useless information which is accumulated in the organizational memory and in some cases prevents fast progress of organizations [9].

To some extent, organizational forgetting and learning are two types of organizational change, including organizational development at two points of time. In the case of forgetting, the organization follows a certain procedure at a point of time and then it does not take long to inactivate it in the next point of time. As Mahmoudvand [2] stated, Wiek and Covaen (1999) explained his observations in the literature of organizational change and distinguished between the changes that were gradually evolving, changing and growing and those which happened suddenly in batches. Considering the above, one of the main goals of organizational agility and organizational forgetting is to achieve organizational effectiveness as a standard for performance evaluation of the organization. Organizational effectiveness is a method with which organizations evaluate successful realization of their tasks through organizational strategies. Simply, effectiveness is usually in the form of an extent, level or degree in which the organization achieves its goals [10]. Organizational effectiveness is the degree or extent to which the organization approaches its intended goals [11]. Organizational effectiveness is a condition in which the intended organization uses limited resources and at the same time is able to achieve a target or targets, according to the established criteria. If we consider a rational model for the organization, organizational effectiveness can be defined as the ability of an organization to achieve its goal [12]. The rational model of goal examines the organization's ability to achieve its goals. This model is associated with both simple and complex organizational effectiveness [11].

\section{Research Background}

A study, investigating the relationship between organizational forgetting and organizational agility in electronic industries of Shiraz, answered to its first research question using the Pearson correlation coefficient analyses and revealed that there was a significant positive relationship between purposeful organizational forgetting and its dimensions with organizational agility [9]. Tabarsa and Mirzadeh [13] explained a variety of organizational forgetting processes and outcomes and justified the role of knowledge management in each of these processes. Another study studied the relationship between job satisfaction and organizational agility and indicated a positive and significant relationship between organizational agility and its subcomponents including responsiveness, competence, flexibility and speed at work with job satisfaction [7].

Zeng and Chen [14], examining the relationship between organizational forgetting and organizational innovation and the mediating effect of organizational learning capability, stated that management of organizational forgetting depend on the priority of organizational learning over organizational innovation. The researchers focused on organizational innovation, intentional (purposeful) organizational forgetting and organizational learning capability and tried to find the relationship between intentional organizational forgetting, organizational learning and organizational innovation. They stated that purposeful organizational forgetting is an important component of 
knowledge management. Gelberson and Levin, in a study entitled "Incorporating Forgetting into Learning Curves”, defined learning curves as graphs that show the extent of the organizational or personal progress. The diagram can be used to determine the progress of the organization when repeating the same action [15].

Moshabbaki and Rabieh, in a study entitled "Intentional Organizational Forgetting (Strategic): The Elixir of Competitiveness in the organization" examining the concept and forms of organizational forgetting given the importance of strategic purposeful organizational forgetting in addition to measuring the level of purposeful organizational forgetting, examined its relationship with charismatic leadership at different levels of the Iranian automobile industry and stated that forgetting is not as easy as learning, and may be harmful or helpful and is perceivable at both dimensions of purposeful and non-purposeful [16]. Ho examined the relationship between organizational health (one of the components of the effectiveness of Parsons' model based on the combinatorial approach of Hoy and Miskel) and job satisfaction and performance of professors at Singapore University and found a significant relationship between effectiveness, job satisfaction and performance [17]. Karamdokht, exploring the relationship between organizational behavior and organizational effectiveness of Babolsar high schools, concluded that there was a significant positive correlation between organizational behavior and organizational effectiveness of school administrators [3]. Towfiq Poor examined managers' leadership style and its relationship with effectiveness of boys' elementary schools in Ardabil and found a significant relationship between leadership styles and school effectiveness. There is a relationship between organizational agility and organizational effectiveness [18].

This study aimed to investigate the relationship of organizational agility and organizational forgetting with organizational effectiveness among staff of the education administration of Zahedan.

There is a relationship between organizational agility and organizational effectiveness.

There is a relationship between organizational forgetting and organizational effectiveness

There is a relationship between organizational agility and components of organizational effectiveness.

There is a relationship between organizational effectiveness and components of organizational agility.

There is a relationship between organizational forgetting and components of organizational agility.

\section{Research Methodology}

Descriptive research method was applied. The population of this study included a total of 645 staff of the education administration of Zahedan who served in the 2013-14 school year. Using the Krejcie-Morgan table, 200 individuals were selected through using stratified random sampling method due to heterogeneity of the population regarding gender. Instruments contained three questionnaires including Organizational Agility [1] which is consisted of 35 items; Organizational Effectiveness Inventory [3] which is developed based on the Parsons's model (AGIL) with 28 items and Organizational Forgetting Inventory, a researcher-made questionnaire adopted by Mahmoudvand [2] from Holan, Philips and Lawrence's (2004), which was developed to measure the level of forgetting consisting of 9 items. In order to examine the content validity, questionnaires were distributed among a number of faculty members of the Department of Management.

\subsection{Reliability of the Questionnaires}

To calculate and determine the reliability of these three questionnaires, Cronbach's alpha coefficient was applied, the results of which are presented in the following tables.

A. Organizational Agility: To evaluate the reliability of this questionnaire, a preliminary study was conducted on a sample of 36 individuals. Afterwards, the reliability coefficient was calculated for each component of organizational agility using SPSS software. To enhance components' reliability coefficient, a number of questions were eliminated. Thereof, the number of questions was reduced from 43 questions to 35 questions (Table 1).

B. Organizational Effectiveness: To assess the reliability of this questionnaire, a preliminary study was conducted on a sample of 36 individuals. Afterwards, the reliability coefficient was calculated for each component of organizational effectiveness using SPSS software. To enhance components' reliability coefficient, a number of questions were eliminated. Thereof, the number of questions was reduced from 28 questions to 24 questions. Karamdokht examined the reliability coefficient of Organizational Effectiveness Questionnaire and reported that this coefficient was 0.91 [3] (Table 2). 
Table 1. Cronbach’s alpha for components of organizational agility.

\begin{tabular}{ccc}
\hline Components & Number of Questions & Cronbach's Alpha \\
\hline Sustainable strategy & $1-4-9-15-16-20$ & 0.68 \\
Compatible design & $11-26-27-28-30-33-34$ & 0.71 \\
Leadership and shared identity & $6-10-12-13-14-17-18-21-24-25-31-32$ & 0.79 \\
Value creation capabilities & $2-3-5-7-8-19-22-23-29-35$ & 0.76 \\
\hline
\end{tabular}

Table 2. Cronbach’s alpha for components of organizational effectiveness.

\begin{tabular}{ccc}
\hline Components & Number of Questions & Cronbach's Alpha \\
\hline Adaption & $5-8-10-12-13-14-17$ & 0.79 \\
Having purpose & $1-2-9-11$ & 0.71 \\
Unity & $3-4-6-7-16-18$ & 0.73 \\
Maintaining patterns & $15-19-20-21-22-23-24$ & 0.75 \\
\hline
\end{tabular}

C. Organizational Forgetting: To evaluate the reliability of this questionnaire, a preliminary study was conducted on a sample of 36 individuals. Afterwards, the reliability coefficient was calculated for each component of organizational forgetting using SPSS software. To enhance components' reliability coefficient, a number of questions were eliminated. Thereof, the number of questions was reduced from 14 questions to 9 questions. Mahmoudvand examined the reliability coefficient of Organizational Forgetting Questionnaire and reported that this coefficient was 0.86 [2].

\subsection{Analysis and Description of the Demographic Data}

In this section, through applying statistical analysis, distribution of the sample in terms of variables including gender, age, level of education, years of service, and types of employee are discussed.

Considering Table 3, it can be mentioned that the majority of participants (186 individuals) were male, i.e. 93\% of the sample, and 14 individuals were female.

With regard to Table 4, it can be stated that the majority of the sample, i.e. $55.5 \%$ of the participants, were in the age group of 40 years old and higher. Afterwards, 21\% of participants were placed in the age group of 36 to 40 years old and $34 \%$ of them were in the age group of 32 to 40 years old. Moreover, 10.5\% of participants were 24 to 32 years old.

With regard to Table 5, it can be asserted that the majority of the sample (61 individuals), i.e. 30.5\% of participants, had 20 to 25 years of service. Afterwards, 59 individuals, 29.5\% of the sample, had 25 years of service and higher. Additionally, 55 individuals, i.e. $27.5 \%$ of the sample, had less than 15 years of service and 25 individuals, $12.5 \%$ of the sample, had 15 to 25 years of service.

Considering Table 6, it can be argued that the majority of the sample (132 individuals), i.e. 66\% of participants, had BA degrees. Afterwards, 40 individuals, 20\% of the sample, had MA degrees. Additionally, 14 individuals, i.e. $7 \%$ of the sample, had associate degrees and 14 individuals, $7 \%$ of the sample, had a diploma.

Regarding Table 7, it can be stated that the majority of the sample (163 individuals), i.e. $81.5 \%$ of participants, were full-time employees. Afterwards, 25 individuals, $12.5 \%$ of the sample, were contract employees and 12 individuals, i.e. $6 \%$ of the sample, were apprentices.

\section{Results}

H1: There is a relationship between organizational agility and organizational effectiveness.

H2: There is a relationship between organizational forgetting and organizational effectiveness.

As can be seen (Table 8), considering the significance of t-value, validity and fitness of the model is confirmed because the chi-square value, the RMSEA value and the ratio of chi-square to df is good and the GFI as well as AGFI values are over $90 \%$. Therefore, these two hypotheses are confirmed. 
Table 3. Frequency distribution related to the variable of gender.

\begin{tabular}{ccc}
\hline Levels & Frequency & Percentage \\
Male & 186 & 93 \\
Female & 14 & 7 \\
Total & 200 & 100 \\
\hline
\end{tabular}

Table 4. Frequency distribution related to the variable of age.

\begin{tabular}{ccc}
\hline Levels & Frequency & Percentage \\
\hline 24 to 32 years old & 21 & 10.5 \\
32 to 36 years old & 25 & 13 \\
36 to 40 years old & 42 & 21 \\
40 years old and higher & 111 & 55.5 \\
Total & 200 & 100 \\
\hline
\end{tabular}

Table 5. Frequency distribution related to the variable of years of service.

\begin{tabular}{ccc}
\hline Levels & Frequency & Percentage \\
\hline Less than 15 years old & 55 & 27.5 \\
15 to 20 years old & 25 & 12.5 \\
20 to 25 years old & 61 & 30.5 \\
25 years old and higher & 59 & 29.5 \\
Total & 200 & 100 \\
\hline
\end{tabular}

Table 6. Frequency distribution related to the variable of level of education.

\begin{tabular}{cccc}
\hline Levels & Frequency & Percentage \\
\hline Diploma & 14 & 7 \\
Associate degree & 14 & 66 \\
BA & 132 & 20 \\
MA and higher & 40 & 100 \\
\hline
\end{tabular}

Table 7. Frequency distribution related to the variable of level of the type of employment.

\begin{tabular}{ccc}
\hline Levels & Frequency & Percentage \\
\hline Contract employees & 25 & 12.5 \\
Apprentices & 12 & 6 \\
Full time employees & 163 & 81.5 \\
Total & 200 & 100 \\
\hline
\end{tabular}

Table 8. The implementation of structural equations between variables.

\begin{tabular}{ccc}
\hline Research Model & Standardized coefficient ( R) & t-value \\
\hline Organizational forgetting-Organizational agility & 0.50 & 6.77 \\
Organizational forgetting-Organizational effectiveness & 0.21 & 3.18 \\
Organizational effectiveness-Organizational agility & 0.62 & 8.64 \\
\hline
\end{tabular}

$\chi^{2}=$ 205.66; $\mathrm{df}=101 ; \mathrm{RMSEA}=0.072 ; \mathrm{GFI}=0.93 ; \mathrm{AGFI}=0.91$. 
H3: There is a relationship between organizational forgetting and components of organizational effectiveness.

As can be seen (Table 9), considering the significance of $t$ value, validity and fitness of the model is confirmed because the chi-square value, the RMSEA value and the ratio of chi-square to df, is good and the GFI as well as AGFI values are over $90 \%$. Therefore, all hypotheses are confirmed.

H4: There is a relationship between organizational agility and components of organizational effectiveness.

As can be seen (Table 10) considering the significance of $t$ value, validity and fitness of the model is confirmed because the chi-square value, the RMSEA value and the ratio of chi-square to df, is good and the GFI as well as AGFI values are over $90 \%$. Therefore, all hypotheses are confirmed.

H5: There is a relationship between organizational effectiveness and components of organizational agility.

As can be seen (Table 11), considering the significance of $t$ value, validity and fitness of the model is confirmed because the chi-square value, the RMSEA value and the ratio of chi-square to df, is good and the GFI as well as AGFI values are over $90 \%$. Therefore, all hypotheses are confirmed.

H6: There is a relationship between organizational forgetting and components of organizational agility.

As indicated in this Table 12, regarding the significance of $t$ value, validity and fitness of the model is confirmed because the chi-square value, the RMSEA value and the ratio of chi-square to df, is good and the GFI as well as AGFI values are over 90\%. Therefore, all hypotheses are confirmed.

Table 9. The implementation of structural equations between variables.

\begin{tabular}{|c|c|c|c|}
\hline Research Model & Standardized Coefficient ( R) & T-Value & Result \\
\hline Organizational forgetting-Unity & 0.32 & 4.79 & Confirmation \\
\hline Organizational forgetting-Compliance & 0.43 & 6.73 & Confirmation \\
\hline Organizational forgetting-Goal acquisition & 0.46 & 7.29 & Confirmation \\
\hline Organizational forgetting-Maintaining patterns & 0.42 & 6.54 & Confirmation \\
\hline
\end{tabular}

$\chi^{2}=15.30 ; \mathrm{df}=6 ; \mathrm{RMSEA}=0.083 ; \mathrm{GFI}=0.93 ; \mathrm{AGFI}=0.91$.

Table 10. The implementation of structural equations between variables.

\begin{tabular}{|c|c|c|c|}
\hline Research Model & Standardized Coefficient ( R ) & T-Value & Result \\
\hline Organizational agility-Unity & 0.61 & 10.86 & Confirmation \\
\hline Organizational agility-Compliance & 0.69 & 13.32 & Confirmation \\
\hline Organizational agility-Goal acquisition & 0.63 & 11.42 & Confirmation \\
\hline Organizational agility-Maintaining patterns & 0.69 & 13.27 & Confirmation \\
\hline
\end{tabular}

$\chi^{2}=14.61 ; \mathrm{df}=6 ; \mathrm{RMSEA}=0.072 ; \mathrm{GFI}=0.93 ; \mathrm{AGFI}=0.91$.

Table 11. The implementation of structural equations between variables.

\begin{tabular}{|c|c|c|c|}
\hline Research Model & Standardized Coefficient (R) & T-Value & Result \\
\hline Effectiveness-Strategy & 0.64 & 11.82 & Confirmation \\
\hline Effectiveness-Value feature & 0.66 & 12.37 & Confirmation \\
\hline Effectiveness-Shared leadership and identity & 0.66 & 12.22 & Confirmation \\
\hline Effectiveness-Compatible design & 0.63 & 11.38 & Confirmation \\
\hline
\end{tabular}

$\chi^{2}=12.22 ; \mathrm{df}=6 ; \mathrm{RMSEA}=0.072 ; \mathrm{GFI}=0.93 ; \mathrm{AGFI}=0.91$.

Table 12. The implementation of structural equations between variables.

\begin{tabular}{cccc}
\hline Research Model & Standardized coefficient (R) & T-Value & Result \\
Forgetting-Strategy & 0.38 & 5.69 & 6.55 \\
Forgetting-Value feature & 0.42 & 5.75 & Confirmation \\
Forgetting-Shared leadership and identity & 0.38 & 6.25 \\
Forgetting-Compatible design & 0.41 & Confirmation \\
\hline
\end{tabular}

$\chi^{2}=13.39 ; \mathrm{df}=6 ;$ RMSEA $=0.081 ; \mathrm{GFI}=0.93 ;$ AGFI $=0.91$. 


\section{Discussion}

In relation to the first question, the results suggested that there was a significant positive correlation between organizational agility and organizational effectiveness. The results of this research are consistent with the results of the study of Bagherzadeh, Baluyi Jamkhaneh and Moafi's who investigated agility capabilities in public organizations focusing on Mazandaran post office as a case study [19]. The results are also in line with the results of Nickpour and Salajegheh who studied the relationship between organizational agility and job satisfaction and found a positive and significant relationship between organizational agility and its components including responsiveness, competence, flexibility and speed at work with job satisfaction [7]. The results are also consistent with the findings of Vinod who explored organizational agility before and after the implementation of "universal design system” and considered twenty indicators for organizational agility [20].

With regard to the second research question, the results showed that there was a significant positive relationship between organizational forgetting and organizational effectiveness. In other words, organizational forgetting can increase organizational effectiveness. The results are consistent with those of Tabarsa and Mirzadeh [13] and Moshabbaki and Rabieh's [16] study entitled "Intentional Organizational Forgetting (Strategic): the Elixir of Competitiveness in the organization” stating that forgetting is not as easy as learning, and may be harmful or helpful and is perceivable at both dimensions of purposeful and non-purposeful. These results are also in line with Haji Azizi, Dokht Esmati and Moradi’s study entitled “Organization Forgetting: A New Approach to Knowledge Management” addressing and examining concepts such as organizational knowledge and organizational learning, organizational forgetting and its role in organizations [21].

\section{Conclusions}

The results of the third research question suggested that there was a significant positive correlation between organizational forgetting and components of organizational effectiveness. In fact, organizational forgetting increases or decreases the influence of the components of organizational effectiveness. The findings are in line with those of Zeng and Chen’s study entitled “The Relationship between Organizational Forgetting and Organizational Innovation: The Mediating Effect of Organizational Learning Capability” stating that management of organizational forgetting depends on the importance of organizational learning to organizational innovation [14]. The results are also consistent with the results of Gelberson and Levin's study entitled “Incorporating Forgetting into Learning Curves” which defined learning curves as graphs that showed the extent of the organizational or personal progress and showed that the diagram could be used to determine the progress of the organization when repeating the same action [15].

The results of the fourth research question suggested that there was a significant positive relationship between the components of organizational effectiveness and organizational agility. This is in line with the studies of Ho [17], Worley and Lawler [1], and Nickpour and Salajegheh [7] which studied the relationship between organizational agility and Job satisfaction and found a positive and significant relationship between organizational agility and its components including responsiveness, competence, flexibility and speed at work with job satisfaction.

The results of the fifth research question suggested that there was a significant positive relationship between the components of organizational agility and organizational effectiveness, i.e. organizational effectiveness can affect the components of organizational agility and increase organizational agility. The findings are consistent with the findings of Ho [17] and Worley and Lawler [1].

The results of the sixth research question indicated that there was a significant positive correlation between the components of organizational agility and organizational forgetting, i.e. forgetting increases the components of organizational agility. The results are consistent with Moshabbaki and Rabieh's [16] study entitled "Intentional Organizational Forgetting (Strategic): The Elixir of Competitiveness in the organization”, and the studies of Zeng and Chen [14] and Karamdokht [13].

\section{Suggestions Regarding the Obtained Results}

As stated earlier, sustainable and flexible strategy has a key role in agility of organizations. Therefore, managers should consider flexibility in adopting strategies in order to avoid problems when facing sudden changes. To acquire agility, educational organizations should draw an exact portrait of future and educational perspective to relatively predict its structures. Given that compatible designs are the most important variables of organizational agility and their effectiveness has been confirmed, the organization should apply structures which enable it to 
quickly respond to external changes. In other words, the educational organization that wants to be agile should possess organic and flexible structures. Managers of educational organizations are suggested to provide a work environment and climate that facilitates organizational agility. According to the findings of this research study, they should assign staff with more authority and responsibility in decision-making to enable them to adopt their creativity and thus provide innovative methods in their work environment.

\section{Limitations}

1. Unwillingness of some staff to respond to the questionnaires.

2. Conservative environments in offices that may have influenced responses to the questionnaires.

3. The effect of personal biases and interests of research participants on research results.

\section{References}

[1] Worley, G.C. and Lawler, E.E. (2010) Agility and Organization Design: A Diagnostic Framework. Organizational Dynamics, 39, 194-204.

[2] Mahmoudvand, A. (2011) Investigating the Relationship between Organizational Forgetting and Organizational Changes in University of Sistan and Balouchestan. MA Thesis of Educational Administration, University of Sistan and Balouchestan, Baluchestan.

[3] Karamdokht, R. (2011) Examining the Relationship between Organizational Behavior and Organizational Effectiveness in Babolsar Secondary Schools. Leadership and Educational Administration Quarterly, 5, 115-126.

[4] Goldman, S.L., Nagel, R.N. and Kenneth, P. (1995) Agile Competitors and Virtual Organizations. Van Note and Reinhold, New York.

[5] Jafarnejad, A. and Shahaei, B. (2007) Organizational Agility and Agile Manufacturing Organization. Ketab-e-Mehraban Publication, Tehran.

[6] Lin, C.T., Chiu, H. and Tseng, Y.H. (2006) Agility Evaluation Using Fuzzy Logic. International Journal of Production Economics, 101, 353-368. http://dx.doi.org/10.1016/j.ijpe.2005.01.011

[7] Nickpour, A. and Salajegheh, S. (2010) Investigating the Relationship between Job Satisfaction and Organizational Agility of Kerman Public Organizations’ Staff. Journal of Management Studies, 7, 169-184.

[8] Dowlat Modeli, M. (2008) Examining the Ways to Achieve the Agility of the Organization. Journal of Web, 72, 5-27.

[9] Sadeghian, R.A., Yaghubi, N.M. and Afrazi, M.E. (2012) Relationship between Intentional Organizational Forgetting and Organization Agility. Journal of Public Administration, 5, 103-120.

[10] Sadeghi, Z. and Mohtashami, R. (2010) Evaluating the Role of Education in Improving Organizational Effectiveness. Journal of Police Human Resource Development, 7, 87-106.

[11] Daft, R.L. (2001) Foundations of the Theory and Design of the Organization. Translated by: Parsaeian, A. and Arabi, M., Office of Management Research, Tehran.

[12] Alagheband, A. (1997) Educational Management. Be'sat Publication, Tehran.

[13] Tabarsa, A. and Mirzadeh, L. (2012) Organizational Amnesia: The Challenge of Knowledge Management. Journal of Strategy, 29, 103-116.

[14] Zeng, J. and Chen, H. (2010) The Relationship between Intentional Organizational Forgetting and Organizational Innovation the Mediating Effect of Organizational Learning Capability. Advanced Management Science (ICAMS), 3, 47-53.

[15] Gelberson, Sh. and Levin, N. (1986) Incorporating Forgetting into Learning Curves. International Journal of Operations \& Production Management, 2, 80-84.

[16] Moshabbaki, A. and Rabieh, M. (2009) Intentional Organizational Forgetting (Strategic): The Elixir of Competitiveness in the Organization. Journal of Humanities, 13, 194-218.

[17] Ho, J. (2000) Managing Organizational Health and Performance in Junior Colleges. The International Journal of Educational Management, 14, 62-73. http://dx.doi.org/10.1108/09513540010315896

[18] Towfiq Poor, H. (2000) Evaluation of Managers' Leadership Style and Its Relationship with Effectiveness of Boys' Elementary Schools in Ardabil's Public Schools in the Academic Year 1997-98. MA Thesis of Educational Management, Faculty of Educational Sciences, Tarbiat Moalem University, Tehran.

[19] Bagherzadeh, M.R., Baluyi Jamkhaneh, E.A. and Moafi, R. (2010) Examining the Status of Agility Capabilities in Government Agencies (A Case Study: Mazandaran Post Office). Journal of Management, 7, 143-167. 
[20] Vinodh, S. (2010) Improvement of Agility and Sustainability: A Case Study in an Indian Rotary Switches Manufacturing Organizational. Journal of Clear Protector, 55, 194-204. http://dx.doi.org/10.1016/j.jclepro.2010.02.018

[21] Haji Azizi, N., Dokht Esmati, M. and Moradi, Sh. (2009) Organizational Forgetting: A New Approach to Knowledge Management. Journal of Research, Science and Information, 25, 317-330. 